\title{
Why do animals differ in their susceptibility to geometrical illusions?
}

\author{
Lynna C. Feng $^{1} \cdot$ Philippe A. Chouinard $^{1} \cdot$ Tiffani J. Howell $^{1} \cdot$ Pauleen C. Bennett $^{1}$
}

Published online: 3 August 2016

(C) Psychonomic Society, Inc. 2016

\begin{abstract}
In humans, geometrical illusions are thought to reflect mechanisms that are usually helpful for seeing the world in a predictable manner. These mechanisms deceive us given the right set of circumstances, correcting visual input where a correction is not necessary. Investigations of non-human animals' susceptibility to geometrical illusions have yielded contradictory results, suggesting that the underlying mechanisms with which animals see the world may differ across species. In this review, we first collate studies showing that different species are susceptible to specific illusions in the same or reverse direction as humans. Based on a careful assessment of these findings, we then propose several ecological and anatomical factors that may affect how a species perceives illusory stimuli. We also consider the usefulness of this information for determining whether sight in different species might be more similar to human sight, being influenced by contextual information, or to how machines process and transmit information as programmed. Future testing in animals could provide new theoretical insights by focusing on establishing dissociations between stimuli that may or may not alter perception in a particular species. This information could improve our understanding of the mechanisms behind illusions, but also provide insight into how sight is subjectively experienced by different animals, and the degree to which vision is innate versus acquired, which is difficult to examine in humans.
\end{abstract}

Keywords Geometrical illusions · Visual processing · Non-human animals

Lynna C. Feng

1.feng@latrobe.edu.au

1 School of Psychology and Public Health, La Trobe University, P.O. Box 199, Bendigo, VIC 3552, Australia
In the "Broken Telephone" game, whispering a message along a chain of humans typically yields a different message at the end relative to the beginning of the chain. Yet sending the same message along hundreds of miles of telephone signal towers results in an exact replica coming through the final speaker. The human auditory system does not replicate incoming information like a machine. Rather, the signal is interpreted. This is one of the primary reasons why, in the game, the resulting output changes from one human to the next - assuming that cognitive abilities such as working memory are intact. Likewise, in the visual system, sensory inputs are transmuted by the brain to generate a perceptual experience.

In humans, visual interpretations can be studied through geometrical illusions, in which some characteristic of the context in which an object is presented induces misperception of the target object such that it looks larger, smaller, longer, shorter, or different along some other physical dimension. Susceptibility to geometrical illusions is cognitively impenetrable, meaning we cannot stop ourselves from perceiving the illusion even when we know it is an illusion (Pylyshyn, 1999). For example, the well-studied Ponzo illusion (see Table 1) typically persists even after we are told that the two horizontal lines are identical in length. Knowledge of the illusion has little, if any, effect on the degree to which it is experienced. This cognitive impenetrability is suggestive that these mechanisms are deep-seated in humans.

Since geometrical illusions occur automatically, persisting even when we know that the phenomenon occurs, it is plausible that they are not uniquely human and that interpretation, and the potential for misinterpretation, of visual signals is widespread throughout biology. Researchers suggest that, for humans, many illusions are rule-based, reflecting application of rules that we apply to visual inputs and that generally aid in perception of our surroundings (Eagleman, 2001; Helmholtz, 
Table 1 Diagrams and descriptions of illusions discussed in this article

Illusion

Description

Two lines of equal length are presented, often one above the other. They are framed by a set of converging lines, such that the upper line, closer to the point of convergence, appears longer than the lower line.

Two equally sized target circles are presented. One is surrounded by small inducer circles while the other is surrounded by large inducer circles. For humans, the target circle surrounded by the small inducers appears larger than the other target circle.

Two lines of equal length are

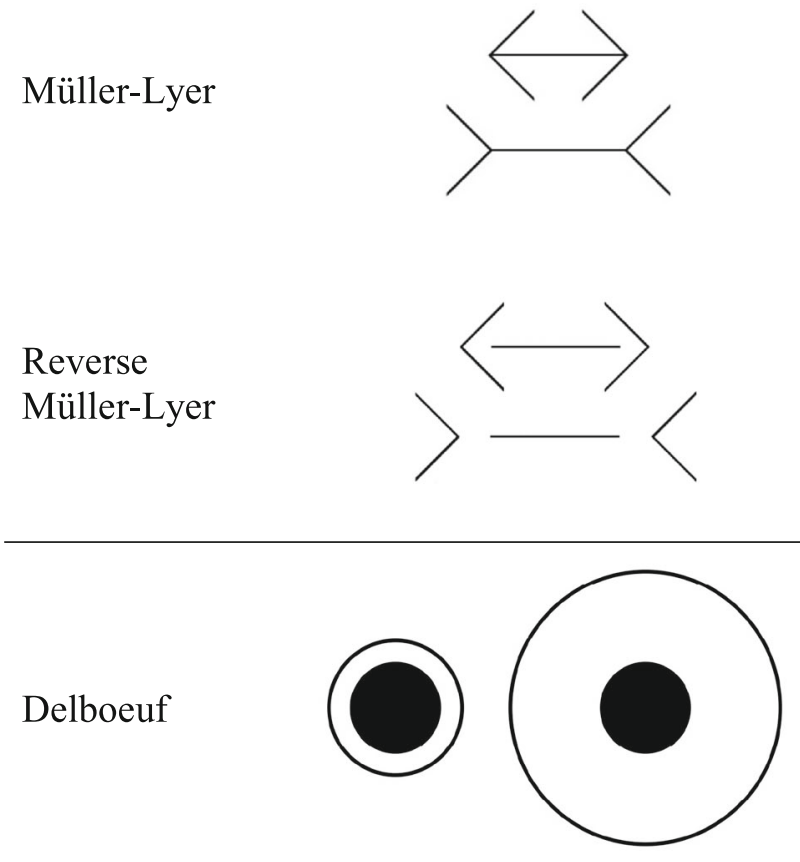

Reverse Müller-Lyer

Oppel-Kundt

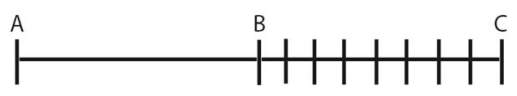
presented. One line has outwardpointing arrows ' $<>$ ' on the ends while the other line has inwardpointing arrows ' $><$ ' on the ends. When the arrows are touching the target line, humans perceive the line with the ' $><$ ' arrows appears longer than the line with the ' $<>$ ' arrows. When the arrows do not touch the target line, the illusion is opposite; the line with the ' $><$ ' arrows appears shorter than the other.

Two equally sized target circles are presented: One is surrounded by a small ring and the other by a larger ring. For humans, the target circle surrounded by the smaller ring appears larger than the other target circle.

Two line segments of equal length are presented (AB and $B C$ ). Segment BC is 'filled' with vertical bars while segment $\mathrm{AB}$ is 'unfilled'. For humans, segment $\mathrm{BC}$ appears longer than $\mathrm{AB}$.

Zöllner

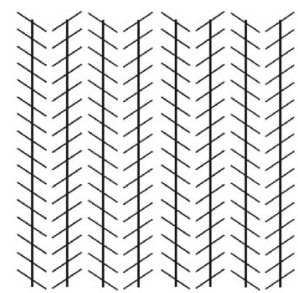

A set of parallel lines are presented with angled hatch marks. For humans, the hatch marks cause the lines to appear non-parallel. 
1867; Gregory, 1980). For example, Gregory’s (1963) Inappropriate Constancy-Scaling theory suggests that illusions such as the Ponzo illusion occur due to the presence of apparent depth cues and the subsequent use of size-constancy rules that help us understand that objects do not normally become physically smaller with increasing distance (see also Sperandio \& Chouinard, 2015; for alternative viewpoints, see Humphrey \& Morgan, 1965 and Newman \& Newman, 1974).

Studies investigating non-human animals' (hereafter referred to as animals) perception of geometrical illusions date back to the 1920s (Révész, 1924). Such examinations allow us to pose the following questions: Are animals more like humans, altering visual inputs, or more like machines, perceiving exact replicas of the inputs they receive? If humans automatically apply rules to interpret visual signals, do animals do the same and, if so, do they apply the same rules as humans? A robust investigation of animal susceptibility to geometrical illusions could answer these questions and shed light on the perceptual abilities of animals. This could have implications for our understanding of visual perception, and perhaps also provide useful information for those who use animals in various applied settings where visual processing is important. Show-jumping horses, for example, must accurately assess the height of obstacles and could be deceived by how they are presented. Search and rescue dogs, and dogs that assist the visually impaired, also rely on accurate visual perceptions to keep themselves and their handlers safe.

Assessments of illusion susceptibility in animals may also shed light onto if, and how, environmental and evolutionary factors impact visual perception. It is possible that different animal species may use different sets of rules to interpret illusory figures designed for humans. If so, an evolutionary basis for visual interpretation might mean that closely related species use similar rules to understand their environment. However, demands that drive the development of these rules may vary greatly across species with different morphologies and those living in different ecological niches (Fujita, Nakamura, Sakai, Watanabe, \& Ushitani, 2012). If so, close evolutionary relationships may be less important than morphology or environmental niche in determining illusion susceptibility.

For example, although humans, and other animals with forward facing eyes, may use a number of monocular cues, such as converging lines, occlusion, and texture gradient, to assess the distance of objects in their environment, they are thought to depend primarily on binocular disparity for depth perception (Wolfe, Kluender, \& Levi, 2012). Animals with eyes located on the sides of their heads have limited binocular vision, suggesting that they must rely more heavily on monocular visual cues to determine how far away objects are. This is of interest in the context of geometrical illusions, as many common examples are argued to be due to humans' misapplication of monocular depth cues (Gregory, 1963; Sperandio \&
Chouinard, 2015; but see Newman \& Newman, 1974 and Fineman \& Carlson, 1973 for alternative viewpoints). Animals that naturally rely more heavily on monocular depth cues might be expected to show greater susceptibility to these illusions or, alternatively, may not be susceptible to them at all.

This possibility is particularly interesting with respect to geometrical illusions with apparent linear perspective cues, such as the Ponzo illusion (see Table 1). Linear perspective cues may not be available for avian species to judge depth when they are flying at heights far greater than trees and buildings. This is why humans, who evolved looking at objects along the horizon, are notoriously poor at judging distance from an aerial view, such as from the window of an airplane. That avian species can accurately judge depth is evident, however, since they effectively catch grounddwelling prey without causing serious harm to themselves. So perhaps birds rely on other distance cues, such as size contrast and texture gradients, in order to judge depth in a precise manner. But what effect might this have on their susceptibility to visual illusions? Do birds fall for the same illusions as terrestrial animals? Do ground-dwelling birds, moreover, differ from those who fly at great heights?

The following review discusses three primary ways in which non-human animal studies contribute to our understanding of both human and animal visual perception and, specifically, susceptibility to different kinds of geometrical illusions. We begin by assessing whether animals are like humans, interpreting visual inputs in ways that produce susceptibility to illusory figures, or if they are more veridical, like machines detecting visual inputs with little or no variability. Next, we consider the impact of environmental and evolutionary pressures on visual perception. The variability of animals' ecological backgrounds provides insight into this question beyond what can be derived from human studies alone. Finally, we argue that well-controlled animal studies can answer questions regarding the innate versus acquired nature of illusion susceptibility, which is difficult, if not impossible, to parse in human participants.

\section{Are animals susceptible to geometrical illusions?}

A PubMed search was performed using the Boolean terms "visual" OR "optical" AND "illusion" with added restrictions to publication type "journal article" and species "non-human animals" and with an English language restriction $(\mathrm{N}=289)$. From these, only papers that used a behavioral paradigm to assess animals' perception of illusions were kept $(n=48)$. Finally, we chose to include only animal studies that incorporated variants of well-known geometrical illusions that alter properties such as size, shape, and parallelism. Other illusions, such as those of colour, luminosity, and illusory contours, were not included (but for a review of non-human animal 
susceptibility to illusory contours see Nieder, 2002). Based on these criteria, 31 papers were selected, investigating the susceptibility of 13 different species to six different illusions. Table 1 provides illustrations and brief descriptions of the six illusions, and the results of the available studies are collated below.

In general, available work confirms that most animals are susceptible to geometrical illusions, albeit with some important exceptions. In the 31 papers selected, there were 34 different studies assessing different species' susceptibility to geometrical illusions. Most $(n=25)$ of these studies reported animals experiencing illusion susceptibility in the same direction as humans; however, four studies reported a lack of susceptibility, and the remaining five studies reported susceptibility in the opposite direction as compared to humans. The diversity of results is surprising, but thus far unexplained.

To draw comparisons across species and illusions, we focus on the most commonly tested illusions: the Ebbinghaus ( $\mathrm{n}$ $=6$ ), Müller-Lyer $(\mathrm{n}=8)$, and Ponzo illusions $(\mathrm{n}=9)$. These are the geometrical illusions highlighted in Rosa Salva et al.'s 2014 review paper on illusion perception in fish, and these three illusions are also some of the most studied illusions in humans (Chouinard, Noulty, Sperandio, \& Landry, 2013). The focus on these particular illusions may reflect researchers' interest in comparing visual processing between humans and other animals. A more ethological approach to visual illusions in animals, using illusions that could potentially serve some purpose in an animal's ecological niche, may yield different results (Kelley \& Kelley, 2014).

\section{Comparison of findings for the Ebbinghaus, Ponzo, and Müller-Lyer illusions}

The Ebbinghaus illusion In the Ebbinghaus illusion, two equally sized target circles are presented. One target circle is surrounded by a ring of small inducer circles while the other is surrounded by a ring of large inducer circles (Table 1). For humans, the target circle surrounded by a ring of small inducers appears larger than the other when they are physically the same size.

Cognitive theories proposed to explain the Ebbinghaus illusion are summarized in Table 2. One proposed explanation for the size misperception is the contour interaction theory (Jaeger, 1978; Goto et al., 2007; Sherman \& Chouinard, 2016). According to this theory, contextual contours that are physically proximal to the inner circle perceptually attract the edges of the inner circle while contextual contours physically further away, past a certain distance, perceptually repel the edges of the inner circle. The former resulting in an inner circle that appears larger and the latter resulting in an inner circle that appears smaller. Alternative explanations for the Ebbinghaus illusion point out potentially misperceived depth cues (inappropriate constancy-scaling theory) and size contrast judgements (size-contrast theory).

In animals, the Ebbinghaus illusion has been investigated in baboons, bottlenose dolphins, homing pigeons, bantam chickens, and redtail splitfin fish (Table 3). The dolphin and redtail splitfin fish were shown to experience the illusion in the same way as humans, perceiving the circle surrounded by large inducer circles to be smaller than the circle surrounded by small inducer circles (Murayama, Usui, Takeda, Kato, \& Maejima, 2012; Sovrano \& Bisazza, 2009).

Perhaps surprisingly, however, baboons did not appear to display any susceptibility to the illusion (Benhar \& Samuel, 1982). Moreover, Nakamura, Watanabe, and Fujita (2008) found that pigeons appeared to experience an opposite illusion, perceiving the circle surrounded by large inducer circles to be larger than the circle surrounded by small inducer circles. In a size classification task, these pigeons judged a target circle surrounded by large inducers to be larger than its true size and a target circle surrounded by small inducers to be smaller than its true size. Subsequent control tests were conducted to rule out the possibility that the pigeons were making choices based on overall size or the size of the gap between the target circle and inducers (Nakamura et al., 2008).

Chickens have also demonstrated susceptibility to the Ebbinghaus illusion in the same unusual direction as pigeons,

Table 2 Cognitive theories proposed to explain the Ebbinghaus illusion

\begin{tabular}{|c|c|c|}
\hline Reference & Cognitive model & Explanation \\
\hline Gregory (1963) & $\begin{array}{l}\text { Inappropriate constancy- } \\
\text { scaling theory }\end{array}$ & $\begin{array}{l}\text { Surrounding inducer circles are perceived as depth cues where depth does not exist, such that the two } \\
\text { target circles are perceived as being at different distances, and thus different sizes }\end{array}$ \\
\hline Jaeger (1978) & Contour interaction theory & $\begin{array}{l}\text { The contours that are proximal to an object perceptually attract while contours that are further away and } \\
\text { past a certain distance perceptually repel, which in turn causes a change in apparent size. This theory } \\
\text { has been used to explain both the Ebbinghaus and Delboeuf illusions }\end{array}$ \\
\hline $\begin{array}{l}\text { McCready } \\
\quad(1985)\end{array}$ & $\begin{array}{l}\text { Angular size-contrast } \\
\text { theory }\end{array}$ & $\begin{array}{l}\text { Depth cues change eye positioning. The surrounding circles induce the eyes to adjust to an apparent } \\
\text { distance, making the object appear a different size }\end{array}$ \\
\hline $\begin{array}{l}\text { Coren and Enns } \\
\quad(1993)\end{array}$ & Size-contrast theory & $\begin{array}{l}\text { Surrounding context circles are perceived as standard and the central target circles are perceived relative } \\
\text { in size, such that smaller surrounding circles cause the central target circle to be overestimated and } \\
\text { larger surrounding circles cause the central target circle to be underestimated }\end{array}$ \\
\hline
\end{tabular}


Table 3 Studies assessing non-human animal susceptibility to the Ebbinghaus Illusion. Unless otherwise specified, all animals showing susceptibility to this illusion were susceptible in the same direction as humans

\begin{tabular}{|c|c|c|c|}
\hline Reference & Sample & Task type & Susceptible? \\
\hline Parron and Fagot (2007) & 8 Papio papio (baboons); 5 males, 3 females, all age 20 & $\begin{array}{l}\text { Two-choice discrimination } \\
\text { task }\end{array}$ & No \\
\hline Nakamura et al. (2008) & $\begin{array}{l}\text { Initial sample: } 6 \text { Columba livia (homing pigeons) } \\
\text { Testing sample (experiment } 1 \text { ): } 5 \\
\text { Testing sample (experiment } 2 \text { ): } 4\end{array}$ & Size-classification task & $\begin{array}{l}\text { Reversed } \\
\quad \text { susceptibility }\end{array}$ \\
\hline Murayama et al. (2012) & 1 Tursiops truncatus (bottlenose dolphin) & $\begin{array}{l}\text { Two-choice discrimination } \\
\text { task }\end{array}$ & Yes \\
\hline Rosa Salva et al. (2013) & $\begin{array}{l}\text { Experiment 1: } 24 \text { Gallus gallus (bantam chickens) } \\
\text { Experiments } 2 \text { and } 3: 12 \text { new Gallus gallus (bantam chickens) } \\
\text { All female; all age } 4 \text { days }\end{array}$ & $\begin{array}{l}\text { Two-choice discrimination } \\
\text { task }\end{array}$ & Yes \\
\hline Nakamura et al. (2014) & $\begin{array}{l}3 \text { Gallus gallus (bantam chickens); } 6 \text { months old, } 2 \text { male, } 1 \\
\text { female }\end{array}$ & Size-classification task & $\begin{array}{l}\text { Reversed } \\
\text { susceptibility }\end{array}$ \\
\hline $\begin{array}{l}\text { Sovrano, Albertazzi, and Rosa Salva } \\
\text { (2015) }\end{array}$ & 8 Xenotoca eiseni (redtail splitfin fish) & $\begin{array}{l}\text { Two-choice discrimination } \\
\text { task }\end{array}$ & Yes \\
\hline
\end{tabular}

although inconsistency across studies makes these results even more difficult to interpret. Rosa Salva, Rugani, Cavazzana, Regolin, and Vallortigara (2013) demonstrated that four-day old chicks perceived the illusion the same as humans. However, Nakamura, Watanabe, and Fujita (2014) tested 6-month old chickens and concluded the opposite. Namely, like pigeons, chickens perceived an opposite Ebbinghaus illusion. A compelling explanation for these disparate results is not yet available, although differences in subject age, training methods, and test design could all potentially contribute. Further investigation is most certainly required to explain these divergent findings.

The Müller-Lyer illusion In the Müller-Lyer illusion, two lines of equal length are presented. One line has inward-pointing arrows ' $><$ ' on the ends while the other has outward-pointing arrows ' $<>$ ' (Table 1). In humans, the line with the ' $><$ ' arrows appears longer than the line with the ' $<>$ ' arrows. Gregory's (1963) inappropriate constancy-scaling theory, discussed previously in this manuscript, has been applied to the Müller-Lyer illusion; the outward pointing arrows are thought to be arranged in a way that makes them appear perceptually closer than the line, while the inward pointing arrows are perceptually further away than the line, inducing relative size-constancy scaling of the lines (Ward, Porac, Coren, \& Girgus, 1977). Alternatively, Pressey's (1972) competing assimilation theory proposes that the longer overall size of the stimulus with inward-pointing arrows ' $><$ ' makes the line appear longer than the stimulus with outward-pointing arrows ' $<>$ '. Table 4 contains additional theories to explain the Müller-Lyer illusion.

When assessing animal susceptibility to the Müller-Lyer illusion, it is crucial to control for the possibility that the animals are making selections based on overall figure size, as choosing the larger overall figure would result in the same responses as susceptibility for the Müller-Lyer illusion in the expected direction. As such, studies require clever control experiments to ensure animals are not merely making choices based on overall size (e.g., Suganuma, Pessoa, Monge-Fuentes, Castro, \& Tavares, 2007). The Müller-Lyer illusion has been investigated in bamboo sharks, homing pigeons, ringneck doves, African gray parrots, capuchin monkeys, rhesus macaques, bantam chickens, and redtail splitfin fish (Table 5).

Of the species tested, only sharks did not appear to be susceptible to the Müller-Lyer illusion (Fuss et al., 2014). All other species tested experienced the illusion in the same way as humans, perceiving the target line to be longer when

Table 4 Cognitive theories proposed to explain the Müller-Lyer illusion

\begin{tabular}{|c|c|c|}
\hline Reference & Cognitive model & Explanation \\
\hline Gregory (1963) & $\begin{array}{l}\text { Inappropriate constancy- } \\
\text { scaling theory }\end{array}$ & $\begin{array}{l}\text { The arrows on the ends of the lines are similar to the corners on the inside and outside of a building or } \\
\text { room, such that the two target lines are perceived as being at different distances, and thus different } \\
\text { sizes }\end{array}$ \\
\hline Pressey (1972) & Assimilation theory & $\begin{array}{l}\text { The ' }><\text { ' arrows at the ends of one line make it appear longer than the line with arrows facing outward ' }< \\
>\text { ' since the overall figure is longer }\end{array}$ \\
\hline $\begin{array}{l}\text { Howe and } \\
\quad \text { Purves (2005) }\end{array}$ & Probabilistic theory & $\begin{array}{l}\text { In natural scenes, ' }><\text { ' arrows are more likely to indicate longer lines, suggesting that the Müller-Lyer } \\
\text { illusion could be due to a probabilistic strategy of visual processing }\end{array}$ \\
\hline Ginsburg (1984) & Selective filtering theory & $\begin{array}{l}\text { We judge visual information with lower spatial frequencies as being further away, causing the inner line } \\
\text { of the ' }><\text { ' arrow to be perceptually rescaled as longer }\end{array}$ \\
\hline
\end{tabular}


Table 5 Studies assessing non-human animal susceptibility to the Müller-Lyer illusion. All animals showing susceptibility to this illusion were susceptible in the same direction as humans

\begin{tabular}{|c|c|c|c|}
\hline Reference & Sample & Task type & Susceptible? \\
\hline Warden and Baar (1929) & 2 adult Streptopelia risoria (ringneck doves) & Two-choice discrimination task & Yes \\
\hline Malott, Malott, and Pokrzywinski (1967) & 5 female Columba livia (homing pigeons) & Generalization gradient test & Yes \\
\hline Nakamura, Fujita, Ushitani, and Miyata (2006) & $\begin{array}{l}3 \text { Columba livia (homing pigeons) } \\
\text { All aged } 9 \text { years; } 1 \text { female, } 2 \text { males }\end{array}$ & Size-classification task & Yes \\
\hline Suganuma et al. (2007) & $\begin{array}{l}10 \text { adult Cebus apella (capuchin monkeys) } \\
5 \text { male, } 5 \text { female; } 6-10 \text { years old }\end{array}$ & Two-choice discrimination task & Yes \\
\hline Pepperberg, Vicinay, and Cavanagh (2008) & 1 male adult Psittacus erithacus (African gray parrot) & Two-choice discrimination task & Yes \\
\hline Nakamura, Watanabe, and Fujita (2009b) & $\begin{array}{l}3 \text { Columba livia (homing pigeons) } \\
\text { All aged } 10 \text { years; } 1 \text { female, } 2 \text { males }\end{array}$ & Size-classification task & Yes \\
\hline Tudusciuc and Nieder (2010) & 2 male Macaca mulatta (rhesus monkeys) & Same or different & Yes \\
\hline Fuss, Bleckmann, and Schluessel (2014) & $\begin{array}{l}8 \text { juvenile Chiloscyllium griseum (bamboo sharks) } \\
4 \text { male, } 5 \text { female }\end{array}$ & Two-choice discrimination task & No \\
\hline Sovrano, da Pos, and Albertazzi (2015) & 6 male Xenotoca eiseni (redtail splitfin fish) & Two-choice discrimination task & Yes \\
\hline
\end{tabular}

inward pointing arrows ' $><$ ' were attached and shorter when outward pointing arrows ' $<>$ ' were attached (Table 2 ). This potentially argues against Gregory's (1963) inappropriate constancy-scaling theory, since few of the species tested are likely to have been exposed to modern architecture.

The results obtained for bamboo sharks and redtailed splitfin fish are particularly interesting given that both are aquatic species, yet the redtailed splitfin fish demonstrated susceptibility to the Müller-Lyer while the bamboo sharks did not. A number of factors could explain this difference: For example, the former is an omnivore that lives in a freshwater habitat and whose diet consists largely of green matter (Animalya-Life, 2016) while the latter is a carnivore that lives in salt water (Lisney \& Cavanaugh, 2003). Differences between the two species may relate to the use of vision to successfully navigate and catch food in these environments, but assessment of other aquatic species is needed to resolve this issue.

The Reversed Müller-Lyer illusion is an alternative version of the Müller-Lyer illusion with arrows that do not touch the target line (Table 1). This modified illusion induces opposite effects in humans: inward pointing arrows ' $><$ ' induce perception of a shorter target line, and outward pointing arrows ' $<$ $>$ ' induce perception of a longer target line. The Reversed Müller-Lyer illusion has been tested in homing pigeons by Nakamura et al. (2006) and again with a new group of pigeons by Nakamura, Watanabe, and Fujita (2009a). The authors of these studies reveal that pigeons do not succumb to this particular illusion (Table 6), which they suggest may relate to the pigeons' small attentive field and inability to attend to both the lines and inducing arrows simultaneously. It will be important to confirm these findings in other species with different evolutionary backgrounds and diverse physiological features.

The Ponzo illusion In the Ponzo illusion, two lines of equal length are presented, often one above the other. They are framed by a set of converging lines, such that the upper line, closer to the point of convergence, appears longer than the lower line (Table 1). The converging lines are thought to be perceived as depth cues, resulting in inappropriate perceptual rescaling (Gregory, 1963; Sperandio \& Chouinard, 2015; see Newman \& Newman, 1974 and Fineman \& Carlson, 1973 for anternative viewpoints). That is, if the top line were further away and projected the same sized image on the retina, based on our understanding of size constancy, the top line must be longer (Ward et al., 1977). As previously discussed, the Ponzo illusion is often attributed to Gregory (1963)'s inappropriate constancy-scaling theory, although alternative explanations, such as Pressey and Epp's (1992) integration field theory have been proposed. These alternative explanations are presented in Table 7.

Research in humans suggests that the Ponzo illusion relies on binocular vision. In humans, the Ponzo illusion appears to

Table 6 Studies assessing non-human animal susceptibility to the Reverse Müller-Lyer Illusion

\begin{tabular}{llll}
\hline Reference & Sample & Task type & Susceptible? \\
\hline Nakamura et al. (2006) & $\begin{array}{c}\text { 3 Columba livia (homing pigeons); } \\
1 \text { female, 2 males, all aged 9 years }\end{array}$ & Size-classification task & No \\
Nakamura et al. (2009a) & $\begin{array}{c}\text { 3 Columba livia (homing pigeons); } \\
1 \text { female, 2 males, all aged 10 years }\end{array}$ & Size-classification task & $\begin{array}{c}\text { Two pigeons - no susceptibility. } \\
\text { One pigeon - reversed susceptibility }\end{array}$ \\
\hline
\end{tabular}


Table 7 Cognitive theories proposed to explain the Ponzo illusion

\begin{tabular}{|c|c|c|}
\hline Reference & Cognitive model & Explanation \\
\hline Gregory (1963) & $\begin{array}{l}\text { Inappropriate constancy- } \\
\text { scaling theory }\end{array}$ & $\begin{array}{l}\text { Converging context lines suggesting depth, such that two target lines are perceived as being at different } \\
\text { distances, and thus different sizes }\end{array}$ \\
\hline $\begin{array}{l}\text { Pressey and Epp } \\
\quad(1992)\end{array}$ & Integration field theory & $\begin{array}{l}\text { Attentional demands are placed between the two target lines and it is the contextual elements that are } \\
\text { present between these two lines that causes us to see the two lines as being perceptually different }\end{array}$ \\
\hline $\begin{array}{r}\text { Prinzmetal and } \\
\text { Beck (2001) }\end{array}$ & Tilt constancy theory & $\begin{array}{l}\text { Size is dependent on where we perceive the location of the end points of each line. The scene causes us } \\
\text { to perceive their locations as different, which causes their apparent size to differ }\end{array}$ \\
\hline
\end{tabular}

be processed after full interocular transfer, suggesting that the illusory perception is processed in area V1 or in higher visual areas (Song, Schwarzkopf, \& Rees, 2011). In animals, the Ponzo illusion has been tested in rhesus macaques, chimpanzees, carneaux pigeons, and horses (Table 8). Although this illusion is thought to require higher levels of visual processing in humans, all species tested have been found to be susceptible to the illusion in the same way as humans. This clearly has profound implications for theoretical explanations of the illusion, suggesting a pressing need for additional research investigating its perception in a range of species.

Other illusions Non-human animal susceptibility has also been assessed in three additional geometrical illusions: the Delboeuf illusion ( $\mathrm{n}=1$; Pan troglodytes), the Oppel-Kundt illusion ( $\mathrm{n}=1$; Rattus norvegicus), and the Zöllner illusion ( $\mathrm{n}$ = 4; Papio papio, Columba livia, Gallus gallus, Macaca mulatta). Table 9 presents proposed mechanisms which may underlie these illusions.

Table 10 summarizes the results of available animal studies. It is of note that inconsistencies in direction of susceptibility, as seen in some of the previous illusions, are evident.

Overall, then, animals seem to misperceive visual stimuli that, in humans, lead to well-established geometrical illusions. However, there are important exceptions and, of particular interest, animals sometimes experience an effect opposite to that observed in humans. This suggests that animals interpret visual inputs rather than processing them in a machine-like manner, but that, in some cases, the rules used are perhaps different from the ones used by humans. Evolutionary pressures are thought to be a key factor driving species differences in visual anatomy (Butler \& Hodos, 2005). Perhaps these variations in evolutionary pressures have also resulted in species differences in visual perception.

\section{Does visual (mis)perception differ across ecological niches?}

As proposed by Fujita et al. (2012), in a review of bird and primate illusory perception, susceptibility to visual illusions may be related to environmental pressures and ecological niche requirements. In accordance with this proposal, we compiled findings from non-human animal species across six geometrical illusions within three different environmental contexts (aquatic, terrestrial, aerial). To the best of our knowledge, at the present time, research on susceptibility to geometrical illusions in nonhuman animals has been restricted to the following species: homing pigeons, ringneck doves, bantam chickens,

Table 8 Studies assessing non-human animal susceptibility to the Ponzo illusion. All animals tested on this illusion were susceptible in the same direction as humans

\begin{tabular}{|c|c|c|c|}
\hline Reference & Sample & Task type & Susceptible? \\
\hline Bayne and Davis (1983) & $\begin{array}{l}4 \text { Macaca mulatta (rhesus monkeys); } 2 \text { male } 2 \text { female, } \\
\text { aged 4-8 years }\end{array}$ & Shape-classification task & Yes \\
\hline Fujita, Blough, and Blough (1991) & 3 male Columba livia (Carneaux pigeons) & Two-choice discrimination task & Yes \\
\hline Fujita (1996) & $\begin{array}{l}2 \text { Macaca mulatta (rhesus monkeys); 8-year-old male, } \\
\text { 7-year-old female }\end{array}$ & Size-classification task & Yes \\
\hline Timney and Keil (1996) & 2 Equus caballus (horses); both female, aged 7 and 15 years & Two-choice discrimination task & Yes \\
\hline Fujita (1997) & $\begin{array}{l}3 \text { Macaca mulatta (rhesus monkeys); } 1 \text { male, } 2 \text { females aged } 5 \\
\text { and } 6 \text { years } \\
1 \text { Pan troglodytes (chimpanzee); female aged } 18 \text { years }\end{array}$ & Size-classification task & Yes \\
\hline Barbet and Fagot (2002) & 4 Papio papio (baboons); 2 male, 2 female & Same or different & Yes \\
\hline Nakagawa (2002) & $\begin{array}{l}16 \text { Rattus norvegicus (Sprague-Dawley rats); all male; } \\
7 \text { months old }\end{array}$ & Size-classification task & Yes \\
\hline Imura, Tomonaga, and Yagi (2008) & 3 Pan troglodytes (chimpanzees) & Two-choice discrimination task & Yes \\
\hline
\end{tabular}


Table 9 Cognitive theories proposed to explain the Delboeuf, Oppel-Kundt, and Zöllner illusions

\begin{tabular}{|c|c|c|c|}
\hline Illusion & Reference & Cognitive model & Explanation \\
\hline Delboeuf & Jaeger (1978) & $\begin{array}{l}\text { Contour interaction } \\
\text { theory }\end{array}$ & $\begin{array}{l}\text { The contours that are proximal to an object perceptually attract while contours } \\
\text { that are further away and past a certain distance perceptually repel, which in turn } \\
\text { causes a change in apparent size. This theory has been used to explain both the } \\
\text { Ebbinghaus and Delboeuf illusions }\end{array}$ \\
\hline Oppel-Kundt & $\begin{array}{l}\text { As cited in Mikellidou } \\
\text { and Thompson (2014) }\end{array}$ & $\begin{array}{l}\text { Filled/unfilled space } \\
\text { theory }\end{array}$ & $\begin{array}{l}\text { Filled spaces look bigger than unfilled spaces, such that the region "filled" with } \\
\text { vertical bars appears longer than the open region of equal length }\end{array}$ \\
\hline \multirow[t]{2}{*}{ Zöllner } & Ward et al. (1977) & $\begin{array}{l}\text { Inappropriate } \\
\text { constancy-scaling } \\
\text { theory }\end{array}$ & $\begin{array}{l}\text { The slanted hash marks suggest depth, such that two target lines appear to converge } \\
\text { into the distance, thus appearing non-parallel }\end{array}$ \\
\hline & $\begin{array}{l}\text { Prinzmetal and Beck } \\
\text { (2001) }\end{array}$ & Tilt constancy theory & $\begin{array}{l}\text { The slanted hash marks influence the perceived slope of the line, such that two } \\
\text { target lines with different direction hash marks appear non-parallel }\end{array}$ \\
\hline
\end{tabular}

African gray parrots, baboons, capuchin monkeys, rhesus monkeys, chimpanzees, redtail splitfin fish, bamboo sharks, horses, rats, and bottlenose dolphins (Fig. 1). In the following section, we discuss how susceptibility differs across these species on the basis of the habitat in which they live - land, air, or water. We note, however, that these categorical distinctions are not necessarily clear cut. For example, arboreal primates could be considered in both aerial and terrestrial categories, but (arguably) appear to experience the world more similarly to terrestrial animals than high-flying birds.

Visual cues used by terrestrial animals to assess depth are most likely similar to those used by humans, whereas those used by birds and aquatic animals are almost certainly different. While humans and other terrestrial animals move mostly on land, birds spend a considerable amount of time in the air, and aquatic animals spend a considerable amount of time under water. The physical differences across the three environments lead to different information being available for animals to assess depth. For example, monocular depth cues, such as texture gradients, lighting, and shading, appear different under water, at least for humans, because light bends as it enters from the air and diffuses as it travels in the medium. Occlusion, a monocular cue which provides powerful depth cues on land, is virtually absent in the air, allowing birds to see further distances along the vertical plane than terrestrial animals are usually permitted to see along the horizontal plane. These examples illustrate how physical conditions across air, land, and water necessitate the processing of different information to judge depth. As a result of these different visual processes, birds, aquatic and terrestrial-dwelling animals may not have the same susceptibility to geometrical illusions. Figure 1 presents demonstrated susceptibility to illusions by species, grouped based on their ecological niche.

Table 10 Studies assessing non-human animal susceptibility to the Delboeuf, Oppel-Kundt, and Zöllner illusions. Unless otherwise specified, all animals showing susceptibility to this illusion were susceptible in the same direction as humans

\begin{tabular}{|c|c|c|c|c|}
\hline Reference & Illusion & Sample & Task type & Susceptible? \\
\hline $\begin{array}{l}\text { Parrish and Beran } \\
\text { (2014) }\end{array}$ & Delboeuf & $\begin{array}{l}3 \text { Pan troglodytes (chimpanzees); } \\
2 \text { males (aged } 39 \text { and } 25 \text { years), } \\
1 \text { female (aged } 42 \text { years) }\end{array}$ & Two-choice discrimination task & Yes \\
\hline $\begin{array}{l}\text { Parrish, Brosnan, } \\
\quad \text { and Beran (2015) }\end{array}$ & Delboeuf & $\begin{array}{l}7 \text { Macaca mulatta (rhesus monkeys); } \\
\text { all adult male } \\
13 \text { Cebus paella (capuchin monkeys); } \\
6 \text { male, } 7 \text { female; all adults }\end{array}$ & $\begin{array}{l}\text { Two-choice discrimination task/ } \\
\text { size-classification task }\end{array}$ & $\begin{array}{l}\text { No (two-choice task). Yes } \\
\quad \text { (size-classification task) }\end{array}$ \\
\hline $\begin{array}{l}\text { Ducharme, Delorme, } \\
\text { and Boulard (1967) }\end{array}$ & Oppel-Kundt & $\begin{array}{l}4 \text { male Rattus norvegicus } \\
\text { (Sprague-Dawley rats) }\end{array}$ & Two-choice discrimination task & $\begin{array}{l}\text { One rat - yes. Three rats - } \\
\text { reversed susceptibility }\end{array}$ \\
\hline $\begin{array}{l}\text { Benhar and Samuel } \\
\text { (1982) }\end{array}$ & Zöllner & 2 Papio papio (baboons); 6 year old males & Two-choice discrimination task & Yes \\
\hline $\begin{array}{l}\text { Watanabe, Nakamura, } \\
\text { and Fujita (2011) }\end{array}$ & Zöllner & $\begin{array}{l}6 \text { Columba livia (homing pigeons) } \\
\text { All male, } 1-13 \text { years old }\end{array}$ & Two-choice discrimination task & Reversed susceptibility \\
\hline $\begin{array}{l}\text { Watanabe, Nakamura, } \\
\text { and Fujita (2013) }\end{array}$ & Zöllner & $\begin{array}{l}3 \text { Gallus gallus (bantam chickens); } \\
2 \text { male, } 1 \text { female; } 3 \text { years old }\end{array}$ & Two-choice discrimination task & Reversed susceptibility \\
\hline $\begin{array}{l}\text { Agrillo, Parrish, and } \\
\text { Beran (2014) }\end{array}$ & Zöllner & $\begin{array}{l}3 \text { Macaca mulatta (rhesus monkeys); all } \\
\text { male, aged } 13,19 \text {, and } 19 \text { years }\end{array}$ & Two-choice discrimination task & Yes \\
\hline
\end{tabular}




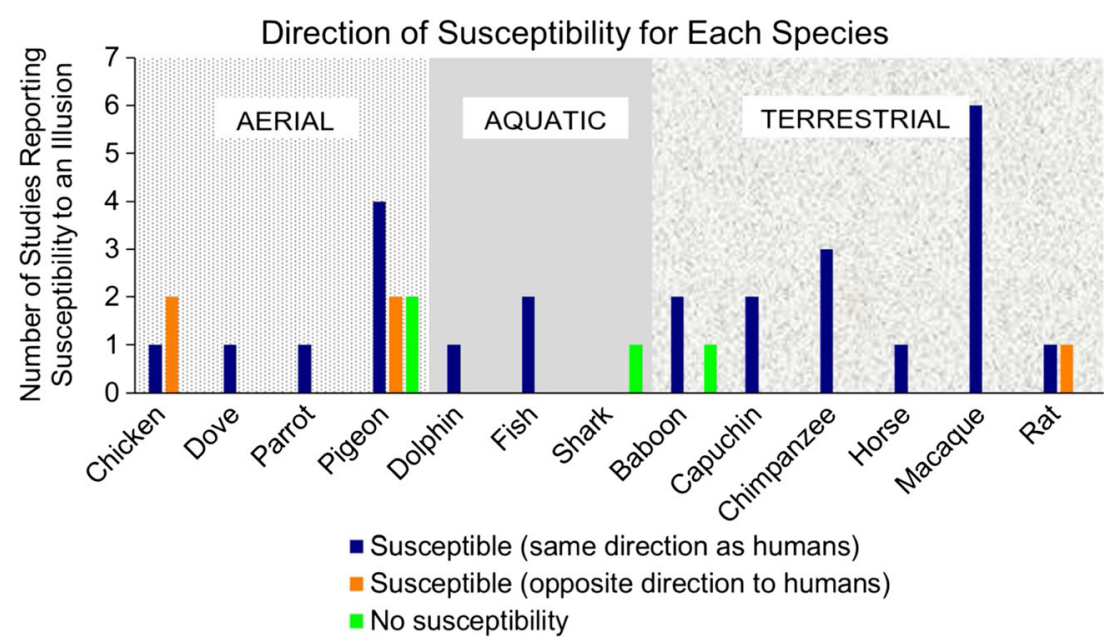

Fig. 1 Direction of susceptibility for each species. The bars reflect the number of studies showing changes in perception going in the same (blue) and opposite (orange) directions as one would expect to see in

humans, as well as the number of studies that did not show illusory effects (green). The species are grouped into three categories: aquatic, aerial, and terrestrial

Aerial For the purposes of this discussion, we placed all avian species in this category, including those with reduced flying abilities, as in the domestic chicken. Domestication of the chicken is a relatively new occurrence within the timeline of evolutionary history. Archaeological evidence suggests chicken domestication occurred less than 5,000 years ago (WoodGush, 1959); hence, this species is arguably better placed in this category, although alternative categories should also be considered. Susceptibility to geometrical illusions has been examined in bantam chickens, homing pigeons, and one African gray parrot.

As Fig. 1 shows, the "aerial" category has the largest discrepancy in terms of perceptual directionality relative to humans. Out of 11 available studies, six demonstrated susceptibility in the same direction as humans, one study with pigeons showed no apparent susceptibility, and the four remaining studies with chickens and pigeons demonstrated susceptibility in the opposite direction as humans. In the 2008 study demonstrating reversed susceptibility of pigeons to the Ebbinghaus illusion, Nakamura et al. suggested that this converse susceptibility could be explained by pigeons' localprecedence in stimulus processing; pigeons have a tendency to focus on individual components of a figure rather than the whole picture. However, there is increasing evidence that lowlevel processes, occurring before visual information arrives at the level of the cortex, contribute to the perceptual experience of this illusion in humans (Song et al., 2011). Thus, low-level properties of the visual display, and not just higher-level cognitive processes, such as local versus global precedence, are partially responsible for driving perceptual changes in size in the direction observed in humans, de-emphasizing plausibility of Nakamura and colleagues' explanation.

Rosa Salva et al. (2014) propose an alternative theory: perhaps these discrepant results could be a product of the intensive training procedure used. In support of this explanation,
Rosa Salva et al. (2013) implemented a more naturalistic training and testing protocol and found that 4-day-old chicks were susceptible to the Ebbinghaus illusion in the same direction as humans, contradictory to findings in six-month-old chickens by Nakamura et al. (2008, 2014). Further investigation into potential factors responsible for the different findings is required.

Aquatic Susceptibility to the Ebbinghaus illusion has been reported to be present in aquatic species. Splitfin fish and one bottlenose dolphin were tested on susceptibility to the Ebbinghaus illusion and demonstrated susceptibility in the same direction as experienced by humans. Bamboo sharks were tested on susceptibility to the Müller-Lyer illusion and did not appear to show susceptibility; however, splitfin fish did demonstrate susceptibility to the Müller-Lyer illusion (Table 5). There have not been any reports of susceptibility or otherwise to the Ponzo illusion in aquatic species. Splitfins and other fish species have also been assessed on a number of non-geometrical illusions and found to be susceptible to all illusions tested (Agrillo, Petrazzini, \& Dadda, 2013).

As previously discussed, one proposed explanation for the Ebbinghaus illusion is the size contrast theory (Coren \& Enns, 1993). The observation that aquatic animals demonstrate susceptibility to this illusion therefore suggests that they may use size contrast in their environment to judge distances and sizes. In contrast, the Müller-Lyer and Ponzo illusions are suggested to rely on the apparent depth created by perceptual corners (Gregory, 1963) and converging lines (Ward et al., 1977), respectively. Such depth cues are not common in water, so the bamboo shark's lack of apparent susceptibility to the Müller-Lyer illusion appears to support this idea. However, redtailed splitfin fish are reportedly susceptibility to the Müller-Lyer illusion. Further investigation with additional aquatic species is required. 
Terrestrial All non-aquatic and non-avian species were placed in the "terrestrial" category, including primarily arboreal species such as the capuchin, although these could alternatively be placed in the "aerial" category. For the most part, terrestrial non-human animals display susceptibility to geometrical illusions. Out of 15 available studies, 13 studies demonstrated susceptibility to an illusion in the same direction as humans, while a single study on baboons showed no apparent susceptibility to the Ebbinghaus illusion and one study on rats showed susceptibility to the Oppel-Kundt illusion that went in the opposite direction as humans (Fig. 1). Thus, apart from these two studies, it would seem that terrestrial animals share more consistently the same perceptual experiences of geometrical illusions as humans. This likely reflects the notion that depth cues and the perceptual demands for understanding the environment are relatively more similar for terrestrial animals than for aquatic and aerial species, although further research is required to investigate the two anomalies already reported, and to establish susceptibility for other terrestrial species. For reasons explained below, it would be particularly instructive to examine species that occupy diverse ecological niches.

\section{Is illusion susceptibility innate or learned?}

Bayesian accounts for explaining geometrical illusions (for example Geisler \& Kersten, 2002) have gained popularity in recent years. Under these models, humans and other animals compute an optimal combination of incoming sensory information and knowledge acquired from prior experience, or "priors," in order to make sense of their surroundings. Susceptibility to geometrical illusions is, then, the subsequent misapplication of the posterior predictive distribution that results from experience with the rules of size constancy and other processes that for the most part facilitate understanding of the world. According to this theory, animals that share similar visual experiences should demonstrate susceptibility to the same illusions.

However, a Bayesian account of visual illusions, based on experience-dependent priors, is incomplete. Recent evidence suggests that perceptual mechanisms underlying certain optical illusions might not depend entirely on personal experience, even in humans. Nine congenitally blind children demonstrated susceptibility to the Ponzo and Müller-Lyer illusions immediately following cataract surgery in just one eye (Gandhi, Kalia, Ganesh, \& Sinha, 2015). These results suggest that processing mechanisms involved in susceptibility to the Ponzo and Müller-Lyer illusions can be experience-independent. Perhaps evolutionary pressures, such as habitat, lead to innate wiring of the nervous system in a way best suited for a particular species to perceive its environment in a meaningful way (Geisler \& Diehl, 2002).
This highlights one of the most significant opportunities provided by the study of animal susceptibility to visual illusions. In human populations, investigating the impact of personal experience on susceptibility to geometrical illusions, other than in the congenitally blind whose sight is subsequently restored, typically requires cross-cultural studies comparing individuals from remote cultures to those from western cultures. Adults from the remote Himba culture in Namibia were found to have reduced susceptibility to visual illusions compared to their western counterparts (de Fockert, Davidoff, Fagot, Parron, \& Goldstein, 2007). With this type of study design, however, it is challenging to rule out alternative hypotheses.

One way to control for confounding factors would be to implement an experimental study with randomly assigned control and experimental groups. Ethical limitations make this impossible in human populations but animal models allow for experience-based theories to be more easily tested because exposure to certain environmental cues, which cannot ethically be manipulated in humans, can be manipulated in animals. For example, perception of the Ponzo illusion is thought to be influenced by experiences of converging lines depicting depth (see Table 7). Thus, we would expect that animals raised without exposure to these depth cues should be less susceptible to the illusion than those raised with exposure to these depth cues. Similarly, one theoretical explanation of the MüllerLyer illusion is that the arrowheads on the lines look like the inside and outside corners of a room or building, which causes misapplication of size constancy mechanisms (Table 4). If perception of the Müller-Lyer illusion is influenced by experience of corners, we would expect that raising animals in environments without corners, such as a round room, would decrease their susceptibility to the illusion. The results of these proposed studies would help determine which theories play a role in explaining animal susceptibility to these illusions, and perhaps shed light on the mechanisms that humans likely use when (mis)perceiving these geometrical stimuli.

Another opportunity concerns the use of electrophysiological recordings at the level of neurons. In humans, such investigations have been carried out in patients with intractable epilepsy who consented to participate in visual experiments while undergoing a procedure to have electrodes placed in the cortex for locating epileptic foci (e.g., Marg \& Adams, 1970). However, opportunities like this are rare. It is perhaps more feasible ethically to use this approach in laboratory animals. One notable study was carried out by Ni, Murray, and Horwitz (2014). In this study electrodes were inserted into neurons of the primary visual cortex (V1) of the macaque monkey. Firing activity in these neurons was recorded while target circles were presented over either a plain or Ponzo illusion background. The results revealed that monkeys were susceptible to the illusion and that their V1 neurons responded in a way that more reflected the perceptual outcome as opposed to the 
retinal input. This is highly suggestive of top-down contextual influences, given that V1 is the first cortical weigh station of visual processing (Sperandio \& Chouinard, 2015). It would be interesting to compare firing responses between a species that succumbs to this illusion versus one that does not.

\section{Future directions and suggested species of interest}

This review discussed current literature on animal susceptibility to geometrical illusions. The results generally suggest that animals are susceptible to geometrical illusions, but some species experience certain illusions differently than do humans or do not seem to be deceived by them at all. This is scientifically informative, although the literature we reviewed may provide an incomplete picture of what has previously been done, given that studies reporting the presence of illusory effects are conceivably easier to publish than those yielding evidence of no illusory effects. Because application of different methodologies may lead to different outcomes, we recommend that future work should focus more on cross-species comparisons, with the aim of establishing double dissociations (i.e., species A misperceives $\mathrm{X}$ but not $\mathrm{Y}$, while species B misperceives $\mathrm{Y}$ but not $\mathrm{X}$ ) while using similar methods. Double dissociations not only provide controlled confirmation that the effects are specific to the study factors under investigation (Firestone \& Scholl, 2014, 2015), but they can also inform us which evolutionary pressures and environmental factors may have caused one species to see things that other species cannot see, as well as the putative mechanisms that underlie these specific visual experiences.

In addition, based on the current species studied, there are a number of questions we are not yet equipped to answer. For example, as previously mentioned, the majority of animals tested in the "terrestrial" grouping were primates. Perhaps their performance similarity compared to humans is a function of being more closely related to humans in ways other than those resulting from shared environmental experiences. In addition, we mentioned how eye placement on the head - affecting the degree of visual field to which an animal has binocular as opposed to monocular vision - might have an impact on susceptibility to some visual illusions. Relatively speaking, primates all have forward facing eyes. We propose that many important questions will not be answered until researchers have investigated a greater diversity of terrestrial species, including those that are genetically distant from humans, and including those with forward- versus side-facing eyes.

Animal visual acuity has not been assessed or controlled for in the study of geometrical illusion susceptibility although, as Table 11 shows, it varies greatly across species. Indeed, to the best of our knowledge, animal studies have not yet addressed the extent to which differences in many basic visual abilities contribute to illusion susceptibility. As a car drives into the distance, it creates a progressively smaller image on the retina. However, size constancy mechanisms help humans perceive it as being further away as opposed to shrinking in size. Given the interdependency of size and distance perception, species with poor visual acuity should perhaps be less susceptible to optical illusions. Since their vision is poor beyond certain distances, these animals have no reason to be able to interpret depth cues present only at those distances. This is perhaps one reason why aquatic animals and some avian species show greater levels of inconsistency in their susceptibility to geometrical illusions than terrestrial animals reviewed. As Table 11 shows, terrestrial animals included in illusion studies tend to have greater visual acuity than either aquatic or avian species. It would be of interest to repeat some of these same experiments in avian species of a predatory nature, which have superior visual acuity than species studied previously.

Overall, the visual abilities of an animal should be considered when investigating susceptibility to geometrical illusions. This information could have implications for animals' ability to perceive visual cues that commonly appear beyond a certain distance or in fine detail,

Table 11 Visual acuity across animal species

\begin{tabular}{|c|c|c|}
\hline Species & $\begin{array}{l}\text { Visual acuity } \\
\text { (cycles/degree) }\end{array}$ & Reference \\
\hline Human & 40 & $\begin{array}{l}\text { Campbell and Green } \\
\text { (1965) }\end{array}$ \\
\hline African Gray Parrot & $\begin{array}{l}\text { Likely between 6-9 } \\
\text { (based on budgerigars } \\
\text { and Bourke's parrots) }\end{array}$ & $\begin{array}{l}\text { Lind, Sunesson, Mitkus, } \\
\text { and Kelber (2012) }\end{array}$ \\
\hline Baboon & Unknown & - \\
\hline Bamboo Shark & Unknown & - \\
\hline Bottlenose Dolphin & 3.3 & $\begin{array}{l}\text { Pepper and } \\
\text { Simmons (1973) }\end{array}$ \\
\hline Capuchin & 63 & Johnson (1914) \\
\hline Chicken & 6.5 & $\begin{array}{l}\text { Gover, Jarvis, } \\
\text { Abeyesinghe, and } \\
\text { Wathes (2009) }\end{array}$ \\
\hline Chimpanzee & 65 & Spence (1934) \\
\hline Horse & 23.3 & Timney and Keil (1992) \\
\hline Pigeon & 17.17 & Ghim and Hodos (2006) \\
\hline Rat & 1.2 & $\begin{array}{l}\text { Silveira, Heywood, and } \\
\text { Cowey (1987) }\end{array}$ \\
\hline Redtail Splitfin Fish & Unknown & - \\
\hline Rhesus Macaque & 53 & Cowey and Ellis (1967) \\
\hline
\end{tabular}

Note: Higher scores in cycles/degree are interpreted as sharper visual acuity. For species where visual acuity is unreported, likely ranges have been provided if visual acuity has been assessed in closely related species 
regardless of whether or not acuity is the limiting factor in a given situation. We suggested that studying birds of prey would be of particular interest. In fact, studying predatory birds, with their forward-facing eyes and extraordinary visual acuity, would provide an interesting comparison to the other species present in the "aerial" category. Animals with alternative mechanisms for depth perception, such as jumping spiders (Nagata et al., 2012), would also provide an interesting platform for assessing the mechanisms underlying illusion susceptibility.

Another species that could provide invaluable insight is the domestic dog. Dogs have occupied the same ecological niche as humans for at least the past 10,000 years (Coppinger \& Coppinger, 2001). They are also the most morphologically diverse species on the planet (Gross, 2010) with eye positions ranging from those of the Bull Terrier, with a hump between its eyes limiting binocular vision, to the infant-like Pug, with frontally positioned eyes. There is evidence to suggest that visual processing (McGreevy, Grassi, \& Harman, 2004) and brain structure (Roberts, McGreevy, \& Valenzuela, 2010) differ between dogs with long noses, such as Greyhounds, and dogs with short noses, such as Pugs. Investigating these breeds' perception of the illusions discussed in this review could begin to clarify factors that predict susceptibility to visual misperceptions.

Ultimately, non-human animals provide unique opportunities to develop and test theories of visual processing, due to their possession of a wider range of experiential, behavioral, and morphological traits than can be accessed in an exclusively human population. As scientists continue to build the body of knowledge surrounding animal visual perception, it should be kept in mind that animals' habitats (i.e., evolutionary pressures), visual capabilities, and other factors such as facial morphology (e.g., animals with predominantly monocular versus binocular vision) vary, justifying an intentional focus on species that differ in these aspects.

In addition to informing general theories of visual perception, animal studies could well provide new insights into how (and if) various animals actually experience sight. After all, if more evidence emerges suggesting that animals' visual experience is subjectively constructed and can be shaped by their environment, as it is in humans, then this raises the particularly intriguing possibility that animals may experience qualia. The question then arises as to whether or not animals might have visual awareness. To further examine this possibility, future investigations could incorporate some of the same tools used to investigate visual awareness in humans, such as binocular rivalry (Blake, 1989) and continuous flash suppression (Tsuchiya \& Koch, 2005). With the emergence of 3D television technology, these methods may be more feasibly applied to animals than they were previously by means of stereoscopes and mirrors. The underlying principle behind these techniques is that perception between competing visual stimuli is bistable and that a resulting perception is subjective, can change with time, and can even be experimentally manipulated.

\section{Conclusions}

In this review, three primary ways in which testing nonhuman animal susceptibility to visual illusions could contribute to our understanding of visual perception were presented. It was demonstrated that some animals do appear to be susceptible to geometrical illusions, at least under some circumstances. This suggests that they interpret visual inputs much like humans do, rather than processing them veridically, as machines might be expected to do. Second, we identified studies in which some animals were shown to not be susceptible to common illusions. On this basis, it was suggested that studying illusion susceptibility in non-human animals, particularly those with varying levels of similarity with humans' ecological niche or evolutionary history, may provide insight into the evolutionary basis of the perception of depth and other visual information. Finally, we highlighted the opportunities provided by animal subjects to assess the impact of individual experience on an individual's susceptibility to geometrical illusions. Although difficult to address in human subjects, the effect of visual experience can be investigated in animals by carefully controlling subjects' exposure to visual cues, such as converging lines and occlusion, and assessing the impact of such protocols on subsequent tests of illusion susceptibility. Overall, animals provide unique opportunities in furthering our understanding of visual perception that are unavailable or at least greatly limited when studying human subjects.

Acknowledgments This review was carried out with the support of a La Trobe University Postgraduate Research Scholarship and a La Trobe University Full Fee Research Scholarship.

\section{References}

Agrillo, C., Parrish, A. E., \& Beran, M. J. (2014). Do rhesus monkeys (Macaca mulatta) perceive the Zöllner illusion? Psychonomic Bulletin \& Review, 21(4), 986-994. doi:10.3758/s13423-0130573-2

Agrillo, C., Petrazzini, M. E., \& Dadda, M. (2013). Illusory patterns are fishy for fish, too. Frontiers in Neural Circuits, 7, 137. doi:10.3389 /fncir.2013.00137

Animalya-Life. (2016). Redtail splitfin. Retrieved June 1, 2016, from http://animalya-life.com/fishes/redtail-splitfin.html 
Barbet, I., \& Fagot, J. (2002). Perception of the corridor illusion by baboons (Papio papio). Behavioural Brain Research, 132(1), 111115. doi:10.1016/S0166-4328(01)00393-X

Bayne, K. L., \& Davis, R. (1983). Susceptibility of rhesus monkeys (Macaca mulatta) to the Ponzo illusion. Bulletin of the Psychonomic Society, 21(6), 476-478. doi:10.3758/BF03330013

Benhar, E., \& Samuel, D. (1982). Visual illusions in the baboon (Papio anubis). Animal Learning \& Behavior, 10(1), 115-118. doi:10.3758 /BF03212056

Blake, R. (1989). A neural theory of binocular rivalry. Psychological Review, 96(1), 145-167. doi:10.1037/0033-295X.96.1.145

Butler, A. B., \& Hodos, W. (2005). Comparative vertebrate neuroanatomy: evolution and adaptation: John Wiley \& Sons.

Campbell, F. W., \& Green, D. G. (1965). Optical and retinal factors affecting visual resolution. Journal of Physiology, 181(3), 576593. doi:10.1113/jphysiol.1965.sp007784

Chouinard, P. A., Noulty, W. A., Sperandio, I., \& Landry, O. (2013). Global processing during the Muller-Lyer illusion is distinctively affected by the degree of autistic traits in the typical population. Experimental Brain Research, 230(2), 219-231. doi:10.1007 /s00221-013-3646-6

Coppinger, R., \& Coppinger, L. (2001). Dogs: A startling new understanding of canine origin, behavior \& evolution. New York, NY: Simon and Schuster.

Coren, S., \& Enns, J. (1993). Size contrast as a function of conceptual similarity between test and inducers. Perception \& Psychophysics, 54(5), 579-588. doi:10.3758/BF03211782

Cowey, A., \& Ellis, C. M. (1967). Visual acuity of rhesus and squirrel monkeys. Journal of Comparative \& Physiological Psychology, 64(1), 80-84. doi:10.1037/h0024821

de Fockert, J., Davidoff, J., Fagot, J., Parron, C., \& Goldstein, J. (2007). More accurate size contrast judgments in the Ebbinghaus Illusion by a remote culture. Journal of Experimental Psychology: Human Perception and Performance, 33(3), 738-742. doi:10.1037/00961523.33.3.738

Ducharme, R., Delorme, A., \& Boulard, M. (1967). The oppel-kundt illusion in the white rat. Perceptual and Motor Skills, 24(3, PT. 2), 1271-1276. doi:10.2466/pms.1967.24.3c.1271

Eagleman, D. M. (2001). Visual illusions and neurobiology. Nature Reviews Neuroscience, 2(12), 920-926. doi:10.1038/35104092

Fineman, M. B., \& Carlson, J. (1973). A comparison of the Ponzo illusion with a textural analogue. Perception \& Psychophysics, 14(1), 31-33.

Firestone, C., \& Scholl, B. J. (2014). "Top-down" effects where none should be found the El Greco fallacy in perception research. Psychological Science, 25(1), 38-46.

Firestone, C., \& Scholl, B. J. (2015). Cognition does not affect perception: Evaluating the evidence for "top-down" effects. Behavioral and Brain Sciences, 1-72.

Fujita, K. (1996). Linear perspective and the Ponzo illusion: A comparison between rhesus monkeys and humans1. Japanese Psychological Research, 38(3), 136-145. doi:10.1111/j.14685884.1996.tb00018.x

Fujita, K. (1997). Perception of the Ponzo illusion by rhesus monkeys, chimpanzees, and humans: Similarity and difference in the three primate species. Perception \& Psychophysics, 59(2), 284-292. doi:10.3758/BF03211896

Fujita, K., Blough, D. S., \& Blough, P. M. (1991). Pigeons see the Ponzo illusion. Animal Learning \& Behavior, 19(3), 283-293. doi:10.3758 /BF03197888

Fujita, K., Nakamura, N., Sakai, A., Watanabe, S., \& Ushitani, T. (2012). Amodal completion and illusory perception in birds and primates. In O. F. Lazareva, T. Shimizu, \& E. A. Wasserman (Eds.), How animals see the world: Comparative behavior, biology, and evolution of vision (pp. 101-116). New York, NY: Oxford University Press. doi:10.1093/acprof:oso/9780195334654.003.0008
Fuss, T., Bleckmann, H., \& Schluessel, V. (2014). The brain creates illusions not just for us: Sharks (Chiloscyllium griseum) can "see the magic" as well. Frontiers in Neural Circuits, 8, 24. doi:10.3389 /fncir.2014.00024

Gandhi, T., Kalia, A., Ganesh, S., \& Sinha, P. (2015). Immediate susceptibility to visual illusions after sight onset. Current Biology, 25(9), R358-R359. doi:10.1016/j.cub.2015.03.005

Geisler, W. S., \& Diehl, R. L. (2002). Bayesian natural selection and the evolution of perceptual systems. Philosophical Transactions of the Royal Society B, 357(1420), 419-448. doi:10.1098/rstb.2001.1055

Geisler, W. S., \& Kersten, D. (2002). Illusions, perception and Bayes. Nature Neuroscience, 5(6), 508-510. doi:10.1038/nn0602-508

Ghim, M., \& Hodos, W. (2006). Spatial contrast sensitivity of birds. Journal of Comparative Physiology A, 192(5), 523-534. doi:10.1007/s00359-005-0090-5

Ginsburg, A. P. (1984). Visual form perception based on biological filtering. In L. Spillman \& B. R. Wooten (Eds.), Sensory experience, adaptation, and perception (pp. 53-72).

Goto, T., Uchiyama, I., Imai, A., Takahashi, S. Y., Hanari, T., Nakamura, S., \& Kobari, H. (2007). Assimilation and contrast in optical illusions. Japanese Psychological Research, 49(1), 33-44. doi:10.1111 /j.1468-5884.2007.00330.x

Gover, N., Jarvis, J. R., Abeyesinghe, S. M., \& Wathes, C. M. (2009) Stimulus luminance and the spatial acuity of domestic fowl (Gallus g. domesticus). Vision Research, 49(23), 2747-2753. doi:10.1016/j. visres.2009.08.011

Gregory, R. L. (1963). Distortion of visual space as inappropriate constancy scaling. Nature, 199(678-91), 1. doi:10.1038/199678a0

Gregory, R. L. (1980). Perceptions as hypotheses. Philosophical Transactions of the Royal Society B, 290(1038), 181-197. doi:10.1098/rstb.1980.0090

Gross, L. (2010). A dog's eye view of morphological diversity. PLoS Biology, 8(8), e1000452. doi:10.1371/journal.pbio.1000452

Helmholtz, H. v. (1867). Handbuch der physiologischen Optik. Leipzig, Germany: Voss.

Howe, C. Q., \& Purves, D. (2005). The Müller-Lyer illusion explained by the statistics of image-source relationships. Proceedings of the National Academy of Sciences USA, 102(4), 1234-1239. doi:10.1073/pnas.0409314102

Humphrey, N. K., \& Morgan, M. J. (1965). Constancy and the geometric illusions. Nature, 206(4985), 744-745. 10.1038/206744b0.

Imura, T., Tomonaga, M., \& Yagi, A. (2008). The effects of linear perspective on relative size discrimination in chimpanzees (Pan troglodytes) and humans (Homo sapiens). Behavioural Processes, 77(3), 306-312. doi:10.1016/j.beproc.2007.07.006

Jaeger, T. (1978). Ebbinghaus illusions: Size contrast or contour interaction phenomena? Perception \& Psychophysics, 24(4), 337-342. doi:10.3758/BF03204250

Johnson, H. M. (1914). Visual pattern-discrimination in the vertebrates II. Comparative visual acuity in the dog, the monkey and the chick. Animal Behavior, 4(5), 340-361. doi:10.1037/h0073121

Kelley, L. A., \& Kelley, J. L. (2014). Animal visual illusion and confusion: The importance of a perceptual perspective. Behavioral Ecology, 25(3), 450-463. doi:10.1093/beheco/art118

Lind, O., Sunesson, T., Mitkus, M., \& Kelber, A. (2012). Luminancedependence of spatial vision in budgerigars (Melopsittacus undulatus) and Bourke's parrots (Neopsephotus bourkii). Journal of Comparative Physiology A, 198(1), 69-77. doi:10.1007/s00359011-0689-7

Lisney, T. J., \& Cavanaugh, R. D. (2003). Chiloscyllium griseum. doi:10.2305/IUCN.UK.2003.RLTS.T41792A10547859.en

Malott, R., Malott, M., \& Pokrzywinski, J. (1967). The effects of outward-pointing arrowheads on the Mueller-Lyer illusion in pigeons. Psychonomic Science, 9(1), 55-56. doi:10.3758 /BF03330756 
Marg, E., \& Adams, J. (1970). Evidence for a neurological zoom system in vision from angular changes in some receptive fields of single neurons with changes in fixation distance in the human visual cortex. Experientia, 26(3), 270-271.

McCready, D. (1985). On size, distance, and visual angle perception. Perception \& Psychophysics, 37(4), 323-334. doi:10.3758 /bf03211355

McGreevy, P., Grassi, T. D., \& Harman, A. M. (2004). A strong correlation exists between the distribution of retinal ganglion cells and nose length in the dog. Brain, Behavior and Evolution, 63(1), 13-22. doi: $10.1159 / 000073756$

Mikellidou, K., \& Thompson, P. (2014). Crossing the line: Estimations of line length in the Oppel-Kundt illusion. Journal of Vision, 14(8), 20. doi:10.1167/14.8.20

Murayama, T., Usui, A., Takeda, E., Kato, K., \& Maejima, K. (2012). Relative size discrimination and perception of the ebbinghaus illusion in a bottlenose dolphin (Tursiops truncatus). Aquatic Mammals, 38(4), 333-342. doi:10.1578/AM.38.4.2012.333

Nagata, T., Koyanagi, M., Tsukamoto, H., Saeki, S., Isono, K., Shichida, Y., ... Terakita, A. (2012). Depth perception from image defocus in a jumping spider. Science, 335(6067), 469-471. doi:10.1126 /science.1211667

Nakagawa, E. (2002). Rats respond to configurations of stimuli. The Psychological Record, 52(4), 531. doi:10.1901/jeab.2006.111-04

Nakamura, N., Fujita, K., Ushitani, T., \& Miyata, H. (2006). Perception of the standard and the reversed Muller-Lyer figures in pigeons (Columba livia) and humans (Homo sapiens). Journal of Comparative Psychology, 120(3), 252-261. doi:10.1037/07357036.120.3.252

Nakamura, N., Watanabe, S., \& Fujita, K. (2008). Pigeons perceive the Ebbinghaus-Titchener circles as an assimilation illusion. Journal of Experimental Psychology: Animal Behavior Processes, 34(3), 375 387. doi:10.1037/0097-7403.34.3.375

Nakamura, N., Watanabe, S., \& Fujita, K. (2009a). Further analysis of perception of reversed müller-lyer figures for pigeons (Columba livia). Perceptual and Motor Skills, 108(1), 239-250. doi:10.2466 /pms.108.1.239-250

Nakamura, N., Watanabe, S., \& Fujita, K. (2009b). Further analysis of perception of the standard Muller-Lyer figures in pigeons (Columba livia) and humans (Homo sapiens): Effects of length of brackets. Journal of Comparative Psychology, 123(3), 287-294. doi:10.1037/a0016215

Nakamura, N., Watanabe, S., \& Fujita, K. (2014). A reversed EbbinghausTitchener illusion in bantams (Gallus gallus domesticus). Animal Cognition, 17(2), 471-481. doi:10.1007/s10071-013-0679-y

Newman, C. V., \& Newman, B. M. (1974). The Ponzo illusion in pictures with and without suggested depth. The American Journal of Psychology, 87(3), 511-516. doi:10.2307/1421393

Ni, A. M., Murray, S. O., \& Horwitz, G. D. (2014). Object-centered shifts of receptive field positions in monkey primary visual cortex. Current Biology, 24(14), 1653-1658.

Nieder, A. (2002). Seeing more than meets the eye: Processing of illusory contours in animals. Journal of Comparative Physiology A, 188(4), 249-260. doi:10.1007/s00359-002-0306-x

Parrish, A. E., \& Beran, M. J. (2014). When less is more: Like humans, chimpanzees (Pan troglodytes) misperceive food amounts based on plate size. Animal Cognition, 17(2), 427-434. doi:10.1007/s10071013-0674-3

Parrish, A. E., Brosnan, S. F., \& Beran, M. J. (2015). Do you see what I see? A comparative investigation of the Delboeuf illusion in humans (Homo sapiens), rhesus monkeys (Macaca mulatta), and capuchin monkeys (Cebus apella). Journal of Experimental Psychology: Animal Learning and Cognition, 41(4), 395-405. doi:10.1037 /xan0000078

Parron, C., \& Fagot, J. (2007). Comparison of grouping abilities in humans (Homo sapiens) and baboons (Papio papio) with the
Ebbinghaus illusion. Journal of Comparative Psychology, 121(4), 405-411. doi:10.1037/0735-7036.121.4.405

Pepper, R. L., \& Simmons, J. V., Jr. (1973). In-air visual acuity of the bottlenose dolphin. Experimental Neurology, 41(2), 271-276. doi:10.1016/0014-4886(73)90268-9

Pepperberg, I. M., Vicinay, J., \& Cavanagh, P. (2008). Processing of the Muller-Lyer illusion by a Grey parrot (Psittacus erithacus). Perception, 37(5), 765-781. doi:10.1068/p5898

Pressey, A. W. (1972). The assimilation theory of geometric illusions: An additional postulate. Perception \& Psychophysics, 11(1), 28-30. doi:10.3758/BF03212677

Pressey, A., \& Epp, D. (1992). Spatial attention in Ponzo-like patterns. Perception \& Psychophysics, 52(2), 211-221. doi:10.3758 /BF03206774

Prinzmetal, W., \& Beck, D. M. (2001). The tilt-consistency theory of visual illusions. Journal of Experimental Psychology: Human Perception and Performance, 27(1), 206. doi:10.1037/00961523.27.1.206

Pylyshyn, Z. (1999). Is vision continuous with cognition? The case for cognitive impenetrability of visual perception. Behavioral and Brain Sciences, 22(3), 341-365. discussion 366-423.

Révész, G. (1924). Experiments on animal space perception. British Journal of Psychology. General Section, 14(4), 387. doi:10.1111 j.2044-8295.1924.tb00151.x

Roberts, T., McGreevy, P., \& Valenzuela, M. (2010). Human induced rotation and reorganization of the brain of domestic dogs. PLoS ONE, 5(7), e11946. doi:10.1371/journal.pone.0011946

Rosa Salva, O., Rugani, R., Cavazzana, A., Regolin, L., \& Vallortigara, G. (2013). Perception of the Ebbinghaus illusion in four-day-old domestic chicks (Gallus gallus). Animal Cognition, 16(6), 895906. doi:10.1007/s10071-013-0622-2

Rosa Salva, O., Sovrano, V. A., \& Vallortigara, G. (2014). What can fish brains tell us about visual perception? Frontiers in Neural Circuits, 8, 119. doi:10.3389/fncir.2014.00119

Sherman, J. A., \& Chouinard, P. A. (2016). Attractive contours of the Ebbinghaus illusion. Perceptual and Motor Skills, 122(1), 88-95.

Silveira, L. C. L., Heywood, C. A., \& Cowey, A. (1987). Contrast sensitivity and visual acuity of the pigmented rat determined electrophysiologically. Vision Research, 27(10), 1719-1731. doi:10.1016/00426989(87)90101-5

Song, C., Schwarzkopf, D. S., \& Rees, G. (2011). Interocular induction of illusory size perception. BMC Neuroscience, 12, 27. doi:10.1186 1471-2202-12-27

Sovrano, V., Albertazzi, L., \& Rosa Salva, O. (2015). The Ebbinghaus illusion in a fish (Xenotoca eiseni). Animal Cognition, 18(2), 533542. doi:10.1007/s10071-014-0821-5

Sovrano, V. A., \& Bisazza, A. (2009). Perception of subjective contours in fish. Perception, 38(4), 579-590. doi:10.1068/p6121

Sovrano, V., da Pos, O., \& Albertazzi, L. (2015). The Müller-Lyer illusion in the teleost fish Xenotoca eiseni. Animal Cognition, 1-10. doi:10.1007/s10071-015-0917-6

Spence, K. W. (1934). Visual acuity and its relation to brightness in chimpanzee and man. Journal of Comparative Psychology, 18(3), 333-361. doi:10.1037/h0075291

Sperandio, I., \& Chouinard, P. A. (2015). The mechanisms of size constancy. Multisensory Research, 28(3-4), 253-283. doi:10.1163 /22134808-00002483

Suganuma, E., Pessoa, V. F., Monge-Fuentes, V., Castro, B. M., \& Tavares, M. C. H. (2007). Perception of the Müller-Lyer illusion in capuchin monkeys (Cebus apella). Behavioural Brain Research, 182(1), 67-72. doi:10.1016/j.bbr.2007.05.014

Timney, B., \& Keil, K. (1992). Visual acuity in the horse. Vision Research, 32(12), 2289-2293. doi:10.1016/0042-6989(92)90092-W

Timney, B., \& Keil, K. (1996). Horses are sensitive to pictorial depth cues. Perception, 25(9), 1121-1128. doi:10.1068/p251121 
Tsuchiya, N., \& Koch, C. (2005). Continuous flash suppression reduces negative afterimages. Nature Neuroscience, 8(8), 1096-1101. doi:10.1038/nn1500

Tudusciuc, O., \& Nieder, A. (2010). Comparison of length judgments and the Mueller-Lyer illusion in monkeys and humans. Experimental Brain Research, 207(3-4), 221-231. doi:10.1007/s00221-010-2452-7

Ward, L. M., Porac, C., Coren, S., \& Girgus, J. S. (1977). The case for misapplied constancy scaling: Depth associations elicited by illusion configurations. American Journal of Psychology, 90(4), 609-620. doi: $10.2307 / 1421735$

Warden, C. J., \& Baar, J. (1929). The Müller-Lyer illusion in the ring dove, Turtur risorius. Journal of Comparative Psychology, 9(4), 275-292. doi:10.1037/h0071052
Watanabe, S., Nakamura, N., \& Fujita, K. (2011). Pigeons perceive a reversed Zöllner illusion. Cognition, 119(1), 137-141. doi:10.1016 j.cognition.2010.10.020

Watanabe, S., Nakamura, N., \& Fujita, K. (2013). Bantams (Gallus gallus domesticus) also perceive a reversed Zöllner illusion. Animal Cognition, 16(1), 109-115. doi:10.1007/s10071-012-0556-0

Wolfe, J. M., Kluender, K. R., \& Levi, D. M. (2012). Sensation \& Perception (3rd ed.). Sunderland, Mass: Sinauer Associates, Inc. Retrieved from http://sites.sinauer.com/wolfe3e/home/startF.htm

Wood-Gush, D. G. M. (1959). A history of the domestic chicken from antiquity to the 19th century. Poultry Science, 38(2), 321-326. doi:10.3382/ps.0380321 